\title{
Splenic vessel patency: is it real menace to perform laparoscopic splenic vessel-preserving distal pancreatectomy
}

\author{
Dae Joon Park, In Woong Han, Sang Hyup Han, Sun Jong Han, Young Hun You, Young Ju Rhu, Jin Seok Heo, \\ Seong Ho Choi, Dong Wook Choi
}

Department of Surgery, Samsung Medical Center, Sungkyunkwan University School of Medicine, Seoul, Korea

\begin{abstract}
Purpose: This study compared the patency of the splenic vessels between laparoscopic and open spleen and splenic vessel-preserving distal pancreatectomy.

Methods: We retrospectively reviewed a database of 137 patients who underwent laparoscopic $(n=91)$ or open $(n=46$ ) spleen and splenic vessel-preserving distal pancreatectomy at a single institute from 2001 through 2015. Splenic vessel patency was assessed by abdominal computed tomography and classified into three grades according to the degree of stenosis.

Results: The splenic artery patency rate was similar in both groups (97.8 vs. 95.7\%, $P=0.779)$. Also, the splenic vein patency rate was not significantly different between the 2 groups (74.7\% vs. 82.6\%, P $=0.521)$. Postoperative wound complication was significantly lower in the laparoscopic group $(19.8 \%$ vs. $28.3 \%, P=0.006)$, and hospital stay was significantly shorter in the laparoscopic group ( 7 days vs. 9 days, $P=0.001$ ) than in the open group. Median follow-up periods were 22 months (3.7-96.2 months) and 31.7 months (4-104 months) in the laparoscopic and open groups, respectively.

Conclusion: Laparoscopic distal pancreatectomy showed good splenic vessel patency as well as open distal pancreatectomy. For this reason, splenic vessel patency is not an obstacle in performing laparoscopic splenic vesselpreserving distal pancreatectomy.

[Ann Surg Treat Res 2019;96(3):101-106]
\end{abstract}

Key Words: Splenic vein, Splenic artery, Pancreatectomy, Laparoscopy, Vascular patency

\section{INTRODUCTION}

Laparoscopic distal pancreatectomy is a feasible and safe operation for benign and premalignant lesions in the pancreas body and tail [1,2]. It results in shorter hospital stay and fewer postoperative complications than open distal pancreatectomy [1-5]. Preservation of the spleen is preferred through distal pancreatectomy for benign or borderline malignant lesions because of the immunologic and hematologic function of the spleen [6]. Also, many surgeons attempt to preserve the splenic vessel because of the significantly high splenic infarct and gastric varices risks shown in splenic vessel-sacrificing distal pancreatectomy [7-12]. Two to fourteen percent of splenic vesselsacrificing distal pancreatectomy were reported requiring
Received August 6, 2018, Revised October 23, 2018, Accepted November 6, 2018

\section{Corresponding Author: In Woong Han}

Department of Surgery, Samsung Medical Center, Sungkyunkwan University School of Medicine, 81 Irwon-ro, Gangnam-gu, Seoul 06351, Korea

Tel: +82-3410-0772, Fax: +82-3410-6980

E-mail: Cardioman76@gmail.com

ORCID code: https://orcid.org/0000-0001-7093-2469
Copyright (C) 2019, the Korean Surgical Society

(c) Annals of Surgical Treatment and Research is an Open Access Journal. All articles are distributed under the terms of the Creative Commons Attribution NonCommercial License (http://creativecommons.org/licenses/by-nc/4.0/) which permits unrestricted non-commercial use, distribution, and reproduction in any medium, provided the original work is properly cited. 
splenectomy for splenic complication [11,12]. There were some studies regarding comparisons of splenic vessel patency after distal pancreatectomy between open and laparoscopic group; however, some discrepancies existed among them $[3,13,14]$. As a result, the purpose of this study is to compare splenic vessel patency after laparoscopic or open splenic vessel-preserving distal pancreatectomy.

\section{METHODS}

\section{Patients and clinical variables}

All the patients who underwent spleen and splenic vesselpreserving distal pancreatectomy from November 2001 to December 2015 at Samsung Medical Center were retrospectively reviewed. The indication of spleen and splenic vesselpreserving distal pancreatectomy was benign or borderline malignant pancreatic tumors located at the tail, the body, or the neck according to the preoperative radiological imaging. There were no indications for laparoscopic or open surgery in this study. The method of surgery was determined by the preference of the surgeon and the patient. Among all patients, 46 patients received open and 91 patients received laparoscopic distal pancreatectomy. All patients who received distal pancreatectomy were routinely assessed via abdominal CT before discharge and follow-up CT scans were performed at least after 3 months after operation. None of the patients underwent chemoradiation during the follow-up period. The Institutional Review Board (IRB) at Samsung Medical Center approved the exemption of this retrospective study (approval number: 2018-08-008). Written informed consent was waived by the IRB.

\section{Operative procedure by laparoscopic method}

The patients were placed in the supine position and support a gel bar under the back for left-sided elevation. The sites of port insertion were umbilicus $(12 \mathrm{~mm})$, subxiphoid $(5 \mathrm{~mm})$, left lower quadrant $(12 \mathrm{~mm})$, left subcostal $(5 \mathrm{~mm})$. After partial omentectomy, identifying tumor location was performed if needed using intraoperative ultrasonography. Also, superior and inferior borders of the body of the pancreas were the first to be dissected until a window between the splenic vessels and posterior border of the pancreas was visible. This procedure allows a nylon tape to be applied around the pancreas for transection with an endoscopic linear staple. After transection of the pancreas, the distal pancreas was dissected meticulously off the splenic vessels in a right-to-left fashion. Most small splenic vessel branches are ligated with a clip and divided with scissors to avoid thermal damage from energy device. Very small branches that could not ligate the pancreas site were divided with an energy device.

\section{Follow-up}

Routine postoperative CT scan was revealed at 4 to 6 days after operation. To evaluate long-term patency of splenic vessels, CT scan was taken at every 3 or 6 months.

\section{Assessment of vessel patency, splenic perfusion and gastric collaterals}

All postoperative CT images were compared with preoperative images to evaluate postoperative changes in vascular patency, and to determine whether the analyzed vessel was native or collateral that developed after surgery following occlusion of the original splenic vessels. Patency of the splenic vessels was classified into three grades according to the degree of stenosis: intact (grade 0), partial occlusion or thrombosis (grade 1), and total occlusion (grade 2) (Fig. 1).

\section{Statistical analysis}

Statistical analysis was performed using IBM SPSS Statistics ver. 23.0 (IBM Co., Armonk, NY, USA). The categorical variables were expressed as number and percentage and were compared between groups using the chi-square test or Fisher exact test as appropriate. Continuous variables were presented as median (range) using the Mann-Whitney U-test. A P-value of $<0.05$ was considered to indicate statistical significance.

\section{RESULTS}

\section{Clinical characteristics}

The clinical characteristics of the patients who underwent laparoscopic $(n=91)$ or open $(n=46)$ surgery are shown in Table 1. There were no significant differences in age, sex, body mass index, or pathology between the 2 groups. However, open groups were significantly higher in American Society of

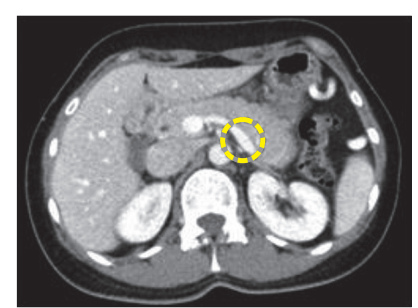

A Grade 0

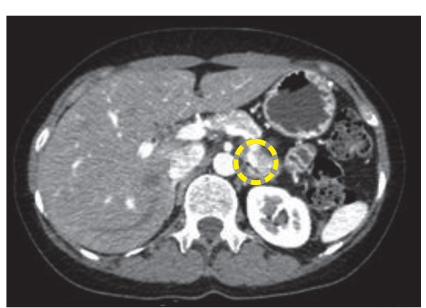

B Grade 1

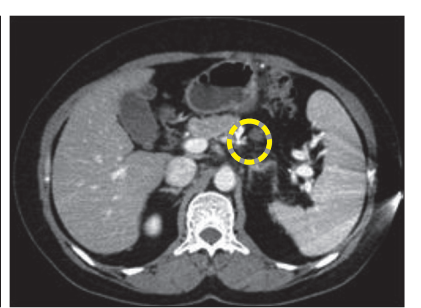

C Grade 2
Fig. 1. Grade of vessel patency. (A) Grade 0: intact. (B) Grade 1: partial occlusion or thrombosis. (C) Grade 3: total occlusion. Yellow circle: splenic vein. 
Anesthesiologists physical status classification and larger tumor size than laparoscopic group.

\section{Postoperative outcomes}

Postoperative outcomes are presented in Table 2. There were no significant differences between the 2 groups in terms of operating time and Postoperative pancreatic fistula (POPF), post operative bleeding, or intraabdominal fluid collection. Laparoscopic group showed significantly lower postoperative wound complication and shorter hospital stay than open group (19.8\% vs. $28.3 \%, \mathrm{P}=0.006$ and 7 vs. 9 days, $\mathrm{P}=0.001$, respectively). There was no mortality in either group. A total of three patients suffered splenic infarction but all of them showed minimal infarction (less than $10 \%$ of total spleen) and no symptom. None of the patients in either group needed further splenectomy.

\section{Postoperative vessel patency, splenic perfusion, and gastric collateral vessels}

Median follow-up periods were 22 months (3.7-96.2 months) and 31.7 months (4-104 months) in the laparoscopic and open groups, respectively. The results of postoperative vessel patency and splenic perfusion are shown in Table 3. The splenic artery patency rate was similar in both groups (97.8 vs. $95.7 \%$, $\mathrm{P}=0.779$ ). Additionally, splenic vein patency rate was not significantly different between the 2 groups ( $74.7 \%$ vs. $72.6 \%, \mathrm{P}$ $=0.521$ ).

\section{Timing of splenic vessel stenosis and occlusion}

Mean timing of splenic artery stenosis/occlusion were 6.1 and 5.4 months in the laparoscopic and open groups, respectively. Mean timing of splenic vein stenosis/occlusion were 6.7 and 5.7 months in the laparoscopic and open groups, respectively. There were no significant different between the 2 groups (Table 3).

Table 1. Clinical characteristics

\begin{tabular}{lcrc}
\hline \multicolumn{1}{c}{ Characteristic } & Laparoscopic group $(\mathrm{n}=91)$ & Open group $(\mathrm{n}=46)$ & P-value \\
\hline Age $(\mathrm{yr})$ & $52(20-81)$ & $52.5(19-83)$ & 0.231 \\
Sex, male:female & $30(33.0): 61(67.0)$ & $22(47.8): 24(52.2)$ & 0.091 \\
BMI $\left(\mathrm{kg} / \mathrm{m}^{2}\right)$ & $23.8(17.3-32.0)$ & $23.8(18.4-33.3)$ & 0.749 \\
ASA PS classification & & & \\
Minimal:moderate:severe & $45: 46: 0$ & $20: 22: 4$ & 0.023 \\
Pathology & & & 0.109 \\
IPMN & $15(16.5)$ & $13(28.3)$ & $6(13.0)$ \\
NET & $23(25.3)$ & $6(13.0)$ & $4(8.7)$ \\
SPT & $21(23.1)$ & $11(23.9)$ & $6(13.0)$ \\
MCN & $12(13.2)$ & $3.0(0.6-8.0)$ & 0.006 \\
SCA & $14(15.4)$ & $6(6.6)$ & \\
Others & $2.0(0.6-7.2)$ & & \\
Tumor size $(\mathrm{cm})$ &
\end{tabular}

Values are presented as median (range) or number (\%).

BMI, body mass index; ASA PS, American Society of Anesthesiologists physical status; IPMN, intraductal papillary mucinous neoplasm; NET, neuroendocrine tumor; SPT, solid pseudopapillary tumor; MCN, mucinous cystic neoplasm; SCA, serous cystadenoma.

Table 2. Postoperative outcome

\begin{tabular}{lccc}
\hline \multicolumn{1}{c}{ Variable } & Laparoscopic group $(\mathrm{n}=91)$ & Open group $(\mathrm{n}=46)$ & P-value \\
\hline Operating time $(\mathrm{min})$ & $160(66-430)$ & $179(75-324)$ & 0.167 \\
Blood loss $(\mathrm{mL})$ & $100(10-1100)$ & $300(50-700)$ & 0.027 \\
Complications & $18(19.8)$ & $13(28.3)$ & 0.263 \\
Pancreatic fistula ${ }^{\text {a }}$ & $14(15.4)$ & $5(10.9)$ & 0.604 \\
Wound complication & $1(1.1)$ & $6(13.1)$ & 0.006 \\
Intra-abdominal fluid collection & $6(5.5)$ & $3(6.5)$ & 0.336 \\
Hemorrhage & $0(0)$ & $1(2.2)$ & 0.336 \\
Postoperative hospital days & $7(3-15)$ & $9(6-26)$ & $<0.001$ \\
\hline
\end{tabular}

Values are presented as median (range) or number (\%).

${ }^{\text {a) }}$ Pancreatic fistula including grades B and C. 
Table 3. Splenic vessel patency, splenic perfusion and gastric collaterals

\begin{tabular}{|c|c|c|c|}
\hline Variable & Laparoscopic group $(\mathrm{n}=91)$ & Open group $(n=46)$ & P-value \\
\hline CT follow-up time (mo) & $22(3.7-96.2)$ & $31.7(4-104)$ & 0.090 \\
\hline Splenic artery patency & & & 0.779 \\
\hline Grade 0 & $89(97.8)$ & $44(95.7)$ & \\
\hline Grade 1 & $1(1.1)$ & $1(2.2)$ & \\
\hline Grade 2 & $1(1.1)$ & $1(2.2)$ & \\
\hline Splenic vein patency & & & 0.521 \\
\hline Grade 0 & $68(74.7)$ & $38(82.6)$ & \\
\hline Grade 1 & $12(13.2)$ & $5(10.9)$ & \\
\hline Grade 2 & $11(12.1)$ & $3(6.5)$ & \\
\hline Splenic infarction & $2(2.2)$ & $1(2.2)$ & 0.993 \\
\hline Collateral vessel & $25(27.5)$ & $7(15.2)$ & 0.109 \\
\hline \multicolumn{4}{|c|}{ Timing of splenic vessel stenosis/occlusion } \\
\hline Mean splenic artery (mo) & 6.1 & 5.4 & 0.788 \\
\hline Mean splenic vein $(\mathrm{mo})$ & 6.7 & 5.7 & 0.473 \\
\hline
\end{tabular}

Values are presented as median (range) or number (\%) unless otherwise indicated.

Table 4. Risk factors for poor splenic vessel patency

\begin{tabular}{lcrc}
\hline \multicolumn{1}{c}{ Variable } & Grade $0(\mathrm{n}=106)$ & Grades 1 and $2(\mathrm{n}=31)$ & P-value \\
\hline Age, $\geq 60 \mathrm{yr}$ & $32(30.2)$ & $9(29.0)$ & 0.902 \\
Female sex & $65(61.3)$ & $20(64.5)$ & 0.747 \\
BMI, $\geq 25 \mathrm{~kg} / \mathrm{m}^{2}$ & $36(34.0)$ & $14(45.2)$ & 0.255 \\
ASA PS classification, II/III & $53(50.0)$ & $19(61.3)$ & 0.268 \\
Large tumor size, $\geq 2.2 \mathrm{~cm}$ & $54(50.9)$ & $13(41.9)$ & 0.355 \\
$\quad$ Laparoscopic surgery & $68(64.2)$ & $23(74.2)$ & 0.298 \\
Long operation time, $\geq 180 \mathrm{~min}$ & $42(39.6)$ & $15(48.4)$ & 0.384 \\
Large amount of blood loss, $\geq 150 \mathrm{~mL}$ & $52(51.5)$ & $19(61.3)$ & 0.338 \\
Long hospital day, $\geq 7$ days & $72(67.9)$ & $20(64.5)$ & 0.722 \\
Pancreatic fistula & $15(14.2)$ & $4(12.9)$ & 0.860 \\
Including A, B,C & $74(69.8)$ & $21(67.7)$ & 0.826 \\
\hline \hline
\end{tabular}

Values are presented as number (\%).

BMI, body mass index; ASA PS, American Society of Anesthesiologists physical status.

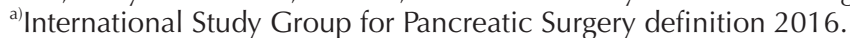

\section{Risk factors for poor splenic vessel patency}

In univariate analysis, there was no significant risk factor for poor splenic vessel patency including all clinical characteristics and operative techniques, and postoperative outcomes (Table 4).

\section{DISCUSSION}

Spleen preserving distal pancreatectomy is the preferred procedure for benign or borderline pancreas body and tail mass because of the important role of the spleen in maintaining immunological function and in reducing the risk of cancer $[6,15]$. Previous studies showed that splenic vessel-sacrificing distal pancreatectomy had a significant risk for splenic infarction and left-sided portal hypertension including gastric varices compared to splenic vessel-preserving distal pancreatectomy $[8,11,12]$. For those reasons, splenic vessel preservation was preferred when a spleen-preserving distal pancreatectomy was performed.

However, splenic vessel-preserving distal pancreatectomy cannot always maintain patency of splenic vessels in both laparoscopic and open surgery. Particularly, the patency of the splenic vein was more often compromised than that of the splenic artery. There are some possible causes. First, dissection of the splenic vein from the pancreas is more difficult; the procedure requires more manipulation because the splenic vein is very closely adherent to the pancreas, and small branches are encountered more frequently than with the splenic artery $[13,16]$. Second, the vein has thinner and less elastic walls than the artery, and it transports blood under lower velocity than the artery. These structural and functional properties may make the splenic vein more susceptible to thrombosis and inflammation [17-19]. A previous study showed that splenic vein 
thrombosis is associated with postoperative pancreatic fistula [20]. Yoon et al. [13,14] said that laparoscopic group showed lower splenic vein patency than open group. Especially, during laparoscopic surgery, there are more difficult and meticulous dissections for the splenic vein. In present study, to overcome these disadvantages of laparoscopic surgery, we attempted to create proper traction of the pancreas and less thermal damage to the splenic vein from the energy device. Moreover, proper interventions for postoperative intra-abdominal fluid collection or pancreatic fistula were done to help decrease the risk of poor splenic vein patency.

Despite the above effort, 37 patients (22.6\%) showed poor splenic vein patency in this study. And among most of them, collateral vessels had developed to maintain splenic venous flow via the short gastric, gastroepiploic, coronary, left adrenal, and mesocolic veins. There was no significant difference between the 2 groups $(P=0.109)$. Furthermore, 14 patients showed total occlusion. Among them, 2 in laparoscopic group and 1 in open group showed gastric varices. However, all of them did not suffer gastrointestinal bleeding. A total of three patients suffered splenic infarction, but all of them showed minimal infarction (less than $10 \%$ of total spleen) and were asymptomatic. None of the patients in either group needed further splenectomy.

In this study, laparoscopic splenic vessel-preserving distal pancreatectomy was associated with shorter postoperative hospital stay and lower wound complication compared with open surgery, with no differences in operative time, intraoperative blood loss, or postoperative complications including POPF. Also, splenic artery and vein patency, splenic infarction, and collateral vessels showed no significant difference between the 2 groups. More experience of laparoscopic surgery and understanding of laparoscopic techniques could make for better postoperative outcomes. If tumor or pancreatitis-induced adhesion to splenic vessels is not severe, laparoscopic splenic vessel-preserving distal pancreatectomy may be indicated for all benign or premalignant lesions of left-sided pancreas.

The limitations of this study are from being a single institute, retrospective study. However, realistically, it is impossible to do a randomized prospective study on this subject. Additionally. there were no comparative results for actual long-term patency between the 2 groups. The results for vascular patency and formation of collaterals may vary depending on the duration of follow-up. In this study, two-thirds of open group that showed poor splenic vessel patency had no more follow-up CT scans after the first CT scan in outpatient clinic. Patency of the splenic vessels should be checked within a month of operation, and long-term follow-up is needed for those with poor splenic vein patency. Further studies are needed to confirm the clinical significance of the short- and long-term outcomes after splenic vessel-preserving distal pancreatectomy.

In conclusion, laparoscopic splenic vessel-preserving distal pancreatectomy is a feasible and safe surgery that maintains good splenic vessel patency with shorter hospital stays and lower wound complications compared to open surgery.

\section{CONFLICTS OF INTEREST}

No potential conflict of interest relevant to this article was reported.

\section{REFERENCES}

1. Eom BW, Jang JY, Lee SE, Han HS, Yoon YS, Kim SW. Clinical outcomes compared between laparoscopic and open distal pancreatectomy. Surg Endosc 2008;22: 1334-8.

2. Matsumoto T, Shibata K, Ohta M, Iwaki K, Uchida H, Yada K, et al. Laparoscopic distal pancreatectomy and open distal pancreatectomy: a nonrandomized comparative study. Surg Laparosc Endosc Percutan Tech 2008;18:340-3.

3. Bruzoni M, Sasson AR. Open and laparoscopic spleen-preserving, splenic vesselpreserving distal pancreatectomy: indi- cations and outcomes. J Gastrointest Surg 2008;12:1202-6.

4. Dai MH, Zhao YP, Liao Q, Liu ZW, Guo JC, Cong L. Laparoscopic distal pancreatectomy: current indications and surgical results. Zhonghua Wai Ke Za Zhi 2006;44: 1022-5.

5. Palanivelu C, Shetty R, Jani K, Sendhilkumar K, Rajan PS, Maheshkumar GS. Laparoscopic distal pancreatectomy: results of a prospective non-randomized study from a tertiary center. Surg Endosc 2007;21:373-7.

6. Di Sabatino A, Carsetti R, Corazza GR.
Post-splenectomy and hyposplenic states. Lancet 2011;378:86-97.

7. Nakamura Y, Matsushita A, Mizuguchi Y, Katsuno A, Uchida E. Study on laparoscopic spleen preserving distal pancreatectomy procedures comparing splenic vessel preservation and non-preservation. Transl Gastroenterol Hepatol 2016;1:27.

8. Partelli S, Cirocchi R, Randolph J, Parisi A, Coratti A, Falconi M. A systematic review and meta-analysis of spleen-preserving distal pancreatectomy with preservation or ligation of the splenic artery and vein. Surgeon 2016;14:109-18. 
9. Tang Y, Tang S, Hu S. The efficacy of spleen-preserving distal pancreatectomy with or without splenic vessel preservation: a meta-analysis. Int J Clin Exp Med 2015:8:17128-39.

10. Yongfei H, Javed AA, Burkhart R, Peters NA, Hasanain A, Weiss MJ, et al. Geographical variation and trends in outcomes of laparoscopic spleen-preserving distal pancreatectomy with or without splenic vessel preservation: a meta-analysis. Int J Surg 2017:47-55.

11. Jain G, Chakravartty S, Patel AG. Spleenpreserving distal pancreatectomy with and without splenic vessel ligation: a systematic review. HPB (Oxford) 2013;15: 403-10.

12. Jean-Philippe Adam, Alexandre Jacquin, Christophe Laurent, Denis Collet, Masson B, Fernandez-Cruz L, et al. Laparoscopic spleen-preserving distal pancreatectomy: splenic vessel preservation compared with the Warshaw technique. JAMA Surg 2013;148:246-52.

13. Yoon YS, Lee KH, Han HS, Cho JY, Ahn KS. Patency of splenic vessels after laparoscopic spleen and splenic vessel-preserving distal pancreatectomy. Br J Surg 2009;96:633-40.

14. Yoon YS, Lee KH, Han HS, Cho JY, Jang JY, Kim SW, et al. Effects of laparoscopic versus open surgery on splenic vessel patency after spleen and splenic vesselpreserving distal pancreatectomy: a retrospective multicenter study. Surg Endosc 2015:29:583-8.

15. Jiang C, Lv GY, Wang YC, Liu XY, Wang GY. Comparison of laparoscopic distal pancreatectomy with or without splenic preservation. Indian J Surg 2015;77(Suppl 3):7837.

16. Kimura W, Inoue T, Futakawa N, Shinkai
H, Han I, Muto T. Spleen-preserving distal pancreatectomy with conservation of the splenic artery and vein. Surgery 1996;120: 885-90.

17. Nordback I, Sisto T. Peripancreatic vascular occlusions as a complication of pancreatitis. Int Surg 1989;74:36-9.

18. Sakorafas GH, Sarr MG, Farley DR, Farnell MB. The significance of sinistral portal hypertension complicating chronic pancreatitis. Am J Surg 2000;179:129-33.

19. Maldjian PD, Zurlow J. Ovarian vein thrombosis associated with a tubo-ovarian abscess. Arch Gynecol Obstet 1997:261: 55-8.

20. Kang CM, Chung YE, Jung MJ, Hwang HK, Choi SH, Lee WJ. Splenic vein thrombosis and pancreatic fistula after minimally invasive distal pancreatectomy. Br J Surg 2014;101:114-9. 